\title{
Интернет-издание "The Independent": структурно-композиционные характеристики и специфика контента
}

\author{
Лущинская О.В. \\ Белорусский государственный университет, \\ Республика Беларусь, 220030, г. Минск, пр. Независимости, 4 \\ E-mail: olgalu805@gmail.com
}

\begin{abstract}
Аннотация. Развитие информационных технологий сказалось на появлении конвергентной журналистики. Несмотря на активную разработку данной тематики, такой его тип, как дискурс конвергентных средств массовой коммуникации, с точки зрения синкретизма его интра- и экстралингвистических характеристик в сравнительно-сопоставительном аспекте в разных журналистских культурах еще недостаточно исследован. В связи с этим авторами поставлена цель выявить и описать структурно-композиционные и содержательные особенности британского конвергентного средства массовой коммуникации "The Independent" с применением авторской интегративной методики дискурсного анализа, которая включает формальные критерии, отражающие организационную структуру и дизайн издания, его количественные показатели; критерии мультимедийных технологий, позволяющие выявить степень присутствия и выраженности явления конвергенции в нем. Результаты исследования могут быть использованы для построения британской модели дискурса конвергентных средств массовой коммуникации, что в дальнейшем позволит сравнить ее с моделями, существующими в других журналистских традициях. Такой подход предоставит возможность реконструировать модели организации современного медиаконтента, а также выявлять, как в них воспринимается и отражается картина мира: в чем проявляется схожесть или отличия, и чем это вызвано.
\end{abstract}

Ключевые слова: конвергентная журналистика, конвергентные средства массовой коммуникации, дискурс конвергентных средств массовой коммуникации, интегративная методика дискурсного анализа, дискурс-категории.

Для цитирования: Лущинская О.В.2020. Интернет-издание "The Independent": структурнокомпозиционные характеристики и специфика контента. Вопросы журналистики, педагогики, языкознания, 39 (4): 555-565. DOI 10.18413/2712-7451-2020-39-4-555-565

\section{Online edition "The Independent": structural and compositional characteristics and the specificity of its content}

\author{
Olga V. Luschinskaya \\ Belarusian State University, \\ 4 Independence Av., Minsk, 220030, The Republic of Belarus \\ E-mail: olgalu805@gmail.com
}

\begin{abstract}
The development of information technologies has affected the emergence of convergent journalism. Despite the active development of this topic by Russian and Belarusian researchers, its type as convergent media discourse has not yet been sufficiently studied in terms of syncretism of its intra - and extralinguistic characteristics in a comparative aspect in different journalistic cultures. In this regard, the authors set a goal to identify and describe the structural, compositional and content features of the British convergent mass communication media "The Independent" using the author's integrative method of
\end{abstract}


discourse analysis, which includes formal criteria that reflect the organizational structure and design of the publication, its quantitative indicators; criteria of multimedia technologies that allow to identify the degree of presence and severity of the phenomenon of convergence in it. The specificity of content is revealed through the representation of extralinguistic criteria using the following discourse categories: audience, communicative attitude, self-identification, space, time, intertextuality, intersubjectivity, intersubjectivity. The "stylistic range" category reflects the textual organization of the British online publication under study. The analysis noted the widespread use of creolized media texts and a large number of hyperlinks in their content. A continuous sampling method was used to analyze the genre diversity in certain categories of the online publication. the results are accompanied by statistical indicators. The results of the research will be used to build a British model of convergent mass media discourse, which will later allow us to compare it with models existing in other journalistic traditions, in particular, the Belarusian and American ones. This approach will provide an opportunity to reconstruct the organization models of modern media content, as well as to identify how they perceive and reflect the picture of the world: what are the similarities or differences, and what causes it.

Keywords: convergent journalism, convergent media, discourse of convergent media, integrative methods of discourse analysis, discourse categories.

For citation: Luschinskaya O.V. 2020. Online edition "The Independent": structural and compositional characteristics and the specificity of its content. Issues in Journalism, Education, Linguistics, 39 (4): 555 565 (in Russian). DOI 10.18413/2712-7451-2020-39-4-555-565

\section{Введение}

Развитие информационных технологий, которые повлияли на многие сферы нашего глобального общества, сказались на появлении конвергентной журналистики, что, в свою очередь, привело к возникновению разных сетевых изданий, информационных интернетпорталов, интернет-изданий, электронных версий печатных СМИ. Конвергентные средства массовой коммуникации (далее - КСМК) функционируют в интернет-пространстве и являются продуктами интернет-журналистики. Они обладают рядом структурносодержательных характеристик, имеют особенности контента, отличаются спецификой освещения различных дискурсивных практик, способами взаимодействия с аудиториями.

В сфере журналистики и, соответственно, в отношении средств массовой коммуникации (СМК) явно намечается тенденция сближения (срастания) разных видов информационных каналов, в результате чего меняются организационная структура, технологические параметры, на смену мономедийному формату приходит мультимедийный. Следует отметить, что активную разработку данной тематики проводят как белорусские [Градюшко, 2014; 2018; Ивченков, 2018а, б; 2019], так и российские исследователи [Воротникова, 2005; Шестеркина, 2011; Пак, 2012; Грабельников, 2013; Ким, 2013; Хелемендик, 2013; Вартанова, 2015; Симкачева, 2015; Бастрон, Желудева, 2016; Бирюкова, 2017; Вырковский, 2017; Олешко, 2018; Баранова, 2019]. Однако предметом рассмотрения в данных исследованиях в своем большинстве являются белорусские или российские СМК. Вне исследовательского поля остаются специфические конвергентные явления в зарубежных СМИ - имеем в виду не общую характеристику этих интернет-изданий, а специфику структурно-композиционного наполнения и контентной организации конкретных СМК. Привлечение широкой эмпирической базы, в нашем случае британского веб-издания "Тhe Independent", позволит выявить мировые тенденции и аспекты их преломления в белорусской медиасфере.

Цель нашего исследования заключается в выявлении и описании структурнокомпозиционных и содержательных особенностей британского конвергентного средства массовой коммуникации "The Independent" с применением авторской интегративной методики дискурсного анализа для реконструкции его медиаконтента и на основе полученных данных построения модели британских КСМК. 


\section{Объекты и методы исследования}

СМК являются объектом исследования многих научных школ и научных направлений, дисциплин. В этих медиа рассматриваются и анализируются разные аспекты: специфика и содержание контента, в частности, медиатекстов; новые жанры и форматы; тематическое наполнение; изучается и описывается картина мира и то, как она отражается в том или ином издании; выявляются лингвистические особенности, явления конвергенции и креолизации медиатекстов и многое другое.

В фокусе наших исследовательских интересов находятся КСМК, функционирующие в разных журналистских культурах (белорусской, британской, американской). Их анализ позволит в дальнейшем построить модели медийного дискурса, сравнить их, выявить общее и различие. В настоящей статье мы проанализируем интернет-издание "The Independent" на основе предложенной нами интегративной методики дискурсного анализа [Лущинская, 2019], которая включает четыре группы критериев для проведения исследования: формальные, мультимедийных технологий, экстра- и интралингвистические критерии.

\section{Результаты и обсуждение}

Интернет-издание "The Independent" является ярким примером современных КСМК и соблюдает черты, которые характерны для них: многоканальность, мультимедийность, интерактивность, отражение событий в режиме реального времени, постоянное обновление информации, обратная связь между производителями медийной продукции и различными ее аудиториями.

Как и любое онлайновое издание, "The Independent" имеет домашнюю страницу, на которой преобладает визуальная информация: большое количество фотографий, как портретных, так и сюжетных, а также ссылок на видеоматериалы, сопровождающие освещаемые события. Каждая новость имеет активированный заголовок. Иногда рядом с ним помещаются активированные названия нескольких статей, связанных между собой единой тематикой.

«Шапка» домашней страницы включает следующие компоненты: в самой верхней части в левом углу размещается логотип газеты (летящий орел на красном фоне) и ее название, под которым можно прочитать слоган «Самый большой качественный цифровой новостной бренд Великобритании», шрифт которого красного цвета. В правой верхней части помещены активированные ссылки на подписку и регистрацию, а также значок меню, содержащий различные рубрики / разделы издания. Ниже находится строка с названиями разделов: «Новости», «Политика» или «Политика США», «Голоса» (в этой рубрике помещены аналитические материалы, содержащие мнения, комментарии журналистов, редакторские статьи, письма в редакцию и др.), «Спорт», «Культура», «Видео», «Лонгриды», «Премиум», «Климат» и ряд других. Отметим, что какие-то рубрики могут добавляться или исключаться, как, например, «Коронавирус: совет» или «Руководство для тех, кто на карантине», которые были актуальными на период пандемии. Многие рубрики имеют тематические блоки. Например, «Новости» включает «Объединенное Королевство», «Мир», «США», «Политика Великобритании», «Брексит», «Технологии», «Наука» и др.

Часто после «шапки» издания помещаются активированные заголовки нескольких статей с фотографией автора и его фамилией - это так называемые blurbs (в пер. означает издательское рекламное объявление), которые рекламируют информацию важных или значимых статей издания, а только потом следует основное событие на текущий момент и представлен список статей, тематически связанных с ним. Обычно эта новость сопровождается видеоинформацией. К заголовкам применяются разные размеры шрифта, что позволяет выделить наиболее значимую новость большим размером. Такое представление и оформление материалов является очень удобным для пользователей, так как им нет необ- 
ходимости искать информацию в разных разделах по заявленной теме. Можно заключить, что читатели получают достаточно полную и всестороннюю информацию о событии.

Для лучшего восприятия и ориентации в предъявляемом материале наряду с классическими черным и белым цветами издание использует красный и светло-синий цвета как в заголовках, названиях рубрик, так и для фона, и желтый цвет - для фона рубрик или разделов. Важное событие, как правило, обозначено ключевым словом Live («B прямом эфире») на желтом фоне. Его содержание обновляется часто, и материал, который добавляется к статье, обозначается конкретным временем. Информация располагается в хронологической последовательности: по убыванию согласно времени размещения новости, что соответствует хронологическому принщипу. В таких статьях обычно освещается несколько событий, связанных между собой.

Публикуемый материал не только имеет активированный заголовок, фотографию, значок видео, но и ключевое тематическое слово или словосочетание, написанное красным шрифтом, что позволяет пользователям быстро определить, какая проблема затрагивается в статье. Частотными ключевыми фразами являются: «технологии», «мода», «преступление», «коронавирус», «наука», «аналитика», «здоровье» и др., есть и единичные ключевые слова, привязанные к теме публикации, например, «день матери».

Ниже размещаются самые свежие и актуальные материалы на разную тематику. Может появиться рубрика «Специальный репортаж» на желтом фоне. Далее следует информация, обозначенная как «Еще больше топовых новостей»: от политических до культурных, происходящих непосредственно как в Великобритании, так и во всем мире. В издании много статей, содержащих наряду с текстовой информацией и видеоинформацию. На иллюстрациях к таким материалам помещен значок «видео», показывающий пользователям возможности посмотреть видеосюжет, который относится к событию. Это свидетельствует о наличии явления конвергенции в интернет-издании. Можно заметить, что важность предъявляемой новости отражается и при помощи большего или меньшего размера иллюстрации. Далее помещаются единичные публикации из разных рубрик и разделов: «Спорт», «Фичерз», «Музыка», «Обзоры», «Наука» и др. После этого появляются основные рубрики, которые были заявлены в «шапке» издания, содержащие ряд статей на тему обозначенного раздела: «Голоса», «Спорт», «Культура», «Новости», «Стиль жизни», «Фотография». Отдельно представлены разделы «Видео», «Технологии», «Бизнес», «Ваучеры», «Спонсируемый».

В нижней части домашней страницы снова повторяется логотип издания, здесь же находятся активированный раздел «На связи», в котором есть ссылка на соцсети «Твиттер» и «Фейсбук», «Наша продукция», «Другие публикации», «Дополнительные услуги», «Правовые вопросы» с соответствующими активированными подразделами. В интернетиздании отсутствует какая-либо рекламная информация, нет и рубрики «Специальные проекты».

Несмотря на то, что издание на домашней странице выстраивает определенную концепцию предъявления информации так же, как и в своих рубриках, иногда сложно понять системно-иерархическую организацию этих материалов именно на домашней странице, так как на ней «перемешаны» статьи из различных разделов, что не позволяет выявить логику их предъявления. Можно предположить, что эти новости вынесены в начало страницы, так как редакцией издания они считаются важными. В разных рубриках повторяются материалы подразделов других рубрик. Такое распределение информации, как нам видится, связано с разными подходами к классификации публикаций: временной принцип, тематический принцип, а также выделение материалов как особенно важных и значимых. В последнем случае на сайте есть рубрика «Премия», или «Награда», в которой содержатся публикации, выделяемые редакцией на фоне других по каким-либо критериям (уникальности, эксклюзивности, значимости). 
В целом можно заключить, что домашняя страница сайта "The Independent" является достаточно удобной для пользователей и несложной для поиска информации и работы с ней. Полагаем, что при разработке дизайна интернет-версии учитывалась аудитория. На странице соблюдается тематический принции предъявления информации.

Медиатексты издания представляют собой мультимедийные коммуникативные nродукmbl: наряду с текстовой информацией в их содержание включается видеоинформация (обычно после заголовка либо в середине статьи), разного рода иллюстративный материал, фотографии, диаграммы, таблицы, графики, слайд-шоу. Присутствуют гиперссылки на другие тексты или статьи, связанные с содержанием медиатекста; используются опции для осуществления обратной связи журналистов и читателей и др., что реализует формальный критерий «способы реализации обратной связи».

Методом сплошной выборки нами были проанализированы 100 материалов рубрики «Новости» за период с середины июня по начало июля 2020 г., в которой мы сфокусировали внимание на таких ее подразделах, как «Объединенное Королевство», «Мир» и «Политика Великобритании». Эти подразделы освещают местные, региональные, национальные, а также мировые события.

Анализ показал следующие результаты: медиатексты в жанре краткого новостного сообщения составили 8 \%; новостные сообщения, в том числе с большим количеством цитат, оказались преобладающими и составили 53 \% от общего количества проанализированных публикаций. Кроме того, в подразделах данной рубрики используется жанр расширенного новостного сообщения - 14 \% от общего количества. Данные жанры относятся к категории информационных. Также в проанализированных блоках присутствовали и аналитические жанры: 8 \% составили информационно-аналитической статьи и 17 \% - новостные тематические статьи. Таким образом, информационные и аналитические жанры находятся в соотношении 75 к $25 \%$.

Информация данных подразделов обновляется часто и оперативно, что репрезентирует критерий «периодичность обновления информации».

В медиатекстах рубрики «Новости» используется очень большое количество цитируемой информации, во многих текстах она является преобладающей на фоне всего сообщения. На момент анализа текстов их тематика была связана с проблемой коронавируса и его последствиями как для самой Великобритании, так и для мира в целом; с международными событиями в Китае, России, Америке, Австралии, Иране, Индии, в ряде европейских стран. Актуальной оставалась тема брексита; освещались выступления и заявления Бориса Джонсона по многим вопросам национального характера в первую очередь; местные новости освещали локальные преступления, правонарушения и другие события.

Для получения более полной информации об электронном издании мы проанализировали его подраздел «Бизнес» (или «Деловые новости»), который является составной частью рубрики «Новости». Домашняя страница повторяет «шапку» издания и его нижнюю часть, что свидетельствует о соблюдении принципа единообразия. Для определения жанрового разнообразия этой подрубрики были проанализированы 100 материалов с ключевыми словами «бизнес» и «бизнес-новости» за период с конца июня по июль 2020 г. Результаты проведенного количественного контент-анализа показали, что в этом разделе присутствуют как информационные, так и аналитические жанры, однако первые являются преобладающими: краткие новостные сообщения составили $11 \%$; новостные сообщения (во многих из них используется большое количество цитируемой информации) - 34 \%; расширенные новостные сообщения (в которых присутствует много цитат и другой уточняющей, дополнительной информации по освещаемой теме) составили 19 \%. Достаточно часто в анализируемом подразделе журналисты используют жанр тематической статьи, в том числе и новостной. Из рассмотренных материалов этот жанр охватывает $22 \%$. Кроме того, используются информационно-аналитические статьи - они составляют 13 \% от общего количества проанализированных публикаций. Встретилась и статья-комментарий, 
составившая всего лишь 1 \%. В сумме аналитические жанры встретились в 36 \% от рассмотренных статей. Эта цифра свидетельствует о том, что издание нацелено не только на передачу в своих медиатекстах определенной информации, но и на ее анализ, объяснение, интерпретацию данных, использование разных аргументов, позволяющих аудитории посмотреть на освещаемые события с разных сторон и более детально. Отметим, однако, что это фактический анализ, базирующийся на данных, статистике, мнениях экспертов, а не личные мнения журналистов.

Медиатексты подраздела «Бизнес» изобилуют статистическим данными и большим количеством цитируемой информации, гиперссылками на другие источники. Тематика связана с вопросами безработицы, а именно, с сокращением количества рабочих мест на разных предприятиях в различных сферах; рядом экономических проблем, вызванных ситуацией из-за коронавируса; планами правительства по преодолению сложной экономической ситуации в стране и др.

Анализ других рубрик и их подразделов показал, что в них явно выражена тенденция к соблюдению принщипа единообразия как в оформлении и представлении информации, так и в структуре медиатекстов.

Интернет-издание "The Independent" учитывает различные интересы пользователей, что видно из большого количества рубрик и названий их подразделов, а также тематического содержания медиатекстов. Дизайн разработан таким образом, чтобы быть понятным, удобным и привлекательным для аудитории и позволить ей быстро находить нужную информацию. Основная целевая аудитория - жители Великобритании, так как тематика связана с этой страной, ее регионами, конкретными географическими местами. Большинство международных новостей также рассматриваются сквозь призму их отношения к стране. Журналисты используют много цитат. В этом случае прослеживается и учитывается дискурс-категория (далее - ДК) аудитория, чтобы дать читателям как можно больше объективной информации «из первых рук». В информационных жанрах аудитория прямо не называется, но она определяется имплицитно. Ее учет в медиатекстах прослеживается на основе выбранных журналистами фактов, различного рода данных, статистической информации, соответствующих цитат, графиков, диаграмм и другой информации, ее понятном и доступном предъявление и объяснении.

Продуцируя медиатекст, автор ставит перед собой определенную цель: проинформировать, убедить, объяснить и др., в то же время учитывая все характеристики потенциального читателя и выбирая способы, как этого достичь. В данном случае реализуется ДК коммуникативная установка. Она реконструируется после прочтения всего материала и его анализа. Так, в статье, опубликованной в издании 15.07.2020 в подразделе «Политика Великобритании» под названием "UK ban on Huawei "seriously damages" trust with China, country's ambassador says" коммуникативную установку можно сформулировать как объяснение читателям возможных и уже наступивших последствий для обеих стран после соответствующих действий Великобритании.

Поскольку преобладающими жанрами основных рубрик издания выступают информационные, то автор репрезентирован в медиатекстах имплицитно (ДК самоидентификация). Реконструкция его / ее портрета возможна на основе информации, которую они используют в текстах, и способов ее композиционного представления. Журналисты стараются быть объективными, факты подтверждают данными экспертов или ссылаются на разные государственные институты, документы и др. Материалы написаны от третьего лица. Как уже неоднократно отмечалось, в медиатекстах используется очень много цитируемой информации, видеоинформации, что делает их именно объективными и непредвзятыми. Даже если статьи представлены в аналитических жанрах, авторы делают много ссылок на мнения экспертов и разного рода аргументы, стараясь открыто не высказывать собственного мнения. В материалах рубрики «Голоса» журналисты уже по-другому акту- 
ализированы в медиатекстах, так как используют 1-е лицо единственного числа, высказывая свое мнение по тому или иному вопросу, что позволяет аудитории эксплицитно понять их точку зрения.

Дискурс-категория время отражает актуальные события, которые происходят на текущий момент. Материалы на веб-сайте обновляются и размещаются оперативно, по мере поступления новостей. В то же время авторы часто в своих сообщениях возвращаются к разным временным периодам. Это обусловлено, с одной стороны, тематически, и, с другой, если нужно показать связь освещаемого события с тем, что происходило раньше, и какая была ситуация в прошлом или, наоборот, что прогнозируется на будущее. Особенно это характерно для материалов деловых новостей, в которых сравнивается статистика и другие данные в разные периоды времени. Для наглядности приведем пример из статьи «Inflation increases to $0.6 \%$ as price of clothes, toys and computer games rises» от 15.07.2020. Автор пишет: "Prices across the category grew by 1.8 per cent, compared with a 4.7 per cent fall a year ago, as the virus had an impact on demand and availability of some games".

В интернет-издании "The Independent" нет отдельной ленты с текущими обновляемыми событиями. На начальных страницах различных рубрик и в их подразделах постоянно появляются свежие новости, которые размещаются на первом месте, а затем располагаются предыдущие события (соблюдается хронологический принцип). В конце домашней страницы есть активированная опция «Архив». В этом блоке информации можно прочитать материалы разных лет.

Дискурс-категория пространство имеет широкую представленность в материалах интернет-издания и отражает географическое пространство, которое определяется в сообщении: названия стран, регионов, городов, континентов и др., например, в подразделе «Мир» статьи обозначаются ключевыми словами: «Европа», «Америка», «Средняя Азия», «Африка», «Австралия» и др. В содержании сообщений географическое пространство может конкретизироваться - называется страна или ее город, регион. Так, в публикации, имеющей ключевое слово «Азия» и размещенной в подразделе «Мир» под названием "New York Times pulls journalists out of Hong Kong due to threat of 'sweeping' new security law" от 15.07.2020, более точно называется географическое пространство: основные - это Гон Конг (упоминается уже в названии) и Китай. Кроме того, освещая событие, автор называет такие города, как Вашингтон, Нью-Йорк, Пекин, Лондон, Сеул и страну Северная Корея, поскольку они имеют непосредственное отношение к публикуемой новости. Приведем пример из статьи: "The move will see all of the Times' digital team in Hong Kong, journalists who deal with breaking news while offices in London and New York are offline, transfer to Seoul in South Korea over the course of the next year".

ДК интертекстуальность является самой частотной в интернет-издании. Во всех медиатекстах журналисты ссылаются на мнения экспертов. Часто в статьях цитаты преобладают над другой текстовой информацией. Этот факт подтверждает непредвзятость публикаций в The Independent. Кроме того, присутствие большого количества гиперссылок во всех текстах, также связано с этой категорией.

Дискурс-категория интерсобытийность прослеживается во многих медиатекстах интернет-издания. В статье, опубликованной в рубрике «Новости» под названием "Dominic Raab claims to be lifelong anti-racist campaigner but says he would not take knee" oT 21.06.2020, «интерсобытийность» репрезентируется несколько раз, что обусловлено описываемой ситуацией и ее контекстом: "NFL star Colin Kaepernick's decision in 2016 to kneel during the US national anthem to protest oppression ignited a global debate, continues to draw the vocal rage of president Donald Trump, and has become synonymous with Black 
Lives Matter...". В данном единичном примере жирным шрифтом выделена текстовая информация, реализующая ДК «интерсобытийность». Кроме того, подчеркнутые выражения являются гиперссылками на другие источники информации, по сути, это отражение еще одной категории - «интертекстуальность» - в ее гипертекстовом преломлении.

Журналисты, освещая новости, не просто сообщают о них, а вписывают их в определенный контекст, ссылаясь на ряд событий, мероприятий и др., связанных с главной новостью, что позволяет читателям увидеть и оценить ситуацию с разных сторон.

В интернет-издании категория интерсубъектность находит широкую репрезентативность, отражая взаимодействие и взаимоотношения участников события. Ссылаясь на определенных субъектов коммуникативной ситуации, авторы вписывают их в контекст, идентифицируют их, и читателям понятно, почему именно эти коммуниканты упоминаются, почему их мнения используются в текстах. В статье "Coronavirus: UK government risks 'sleepwalking country into winter of discontent', warns Nobel Prize-winning scientist", опубликованной в подразделе «Политика Великобритании» от 21.07.2020, автор пишет: "Professor Sir Paul Nurse, a distinguished scientist and director of the Francis Crick Institute, criticised what he described as a "pass the parcel" approach and said it was unclear who was responsible for various aspects of the coronavirus strategy". Жирным шрифтом мы выделили участника события и идентифицирующую информацию о нем. Кроме того, детальное представление информации о коммуникантах описываемого события имплицитно реализует еще один тип взаимодействия - «автор - аудитория», который репрезентируется данной категорией.

Дискурс-категория стилистический диапазон связана с лингвистической реализацией медиатекстов, в частности, с их лексическим наполнением. Кроме того, она отражает характеристики целостности, завершенности и связности сообщений. Последняя, наряду с лексическими, грамматическими, стилистическими и композиционными средствами, представлена и гипертекстовыми средствами связи (цвет, подчеркивание, ссылки, иконические вставки и др). Одним из способов завершения материалов в англоязычных СМК является использование цитат. Именно в новостных публикациях журналисты часто используют цитату в последнем абзаце.

\section{Заключение}

Таким образом, британское интернет-издание "The Independent" представляет собой целостную дискурсную систему с выстроенными иерархическими отношениями. Оно характеризуется наличием структурно-композиционных особенностей и дизайнерских приемов, а также спецификой контента. Широко представлено явление конвергенции как непосредственно в самом издании, так и в содержании его медиатекстов, тем не менее текстовая информация является базовой. Использование иллюстративной информации, главным образом фотографий в публикациях, свидетельствует о наличии явления креолизации. Освещение событий в содержании медиатекстов происходит с учетом репрезентации ключевых дискурс-категорий: аудитория, коммуникативная установка, самоидентификация, время, пространство, интертекстуальность, интерсобытийность и интерсубъектность, которые реализуют экстралингвистические параметры интернет-издания на фоне стилистического и жанрового диапазона.

Данные, полученные в ходе проведенного анализа, можно использовать при построении обобщенной модели британских конвергентных средств массовой коммуникации; сравнить ее с моделями, которые существуют в других журналистских традициях; установить специфику методологии творчества в этих традициях и выявить схожие и отличительные черты в репрезентации медиаконтента с учетом субъект-субъектных и субъ- 
ект-предметных отношений, что поможет «увидеть» и понять разные взгляды, приоритеты, подходы к освещению событий; определить системы ценностей в восприятии картины мира и ее реализации в различных конвергентных СМК.

Предложенный в исследовании авторский подход к анализу КСМК можно использовать при работе с разными типами медийного дискурса для выявления их специфики и функционирования в современной отечественной и зарубежной журналистике.

\section{Список литературы}

1. Баранова Е.А. 2019. Медиаконвергенция как системообразующий фактор трансформации института СМИ. Автореф. дис. ... докт. филол. наук. Москва, 30 с.

2. Бастрон А.А., Желудева Е.В. 2016. Медиаконвергенция в журналистике: от классики к универсальности. Вестник РГГУ. Сер. Документоведение и архивоведение, информатика, защита информации и информационная безопасность, 3(5): 33-45.

3. Бирюкова Т.А. 2017. Гипертекстовая онлайн-журналистика: история возникновения (на примере электронного журнала Feed). Вестник Московского ун-та. Сер. 10. Журналистика, 3: 89-109.

4. Вартанова Е. Л. 2015. Новые медиа как культурное пространство современного общества. МедиаАльманах, 4(69): 8-10.

5. Воротникова Ю.С. 2005. Реализация новостного дискурса в электронных англоязычных СМИ. Автореф. дис... канд. филол. наук. С.-Петербург, 20 с.

6. Вырковский А.В. 2017. Управление процессами создания журналистского текста в печатных и онлайновых СМИ. Автореф. дис... докт. филол. наук. Москва, 61 с.

7. Грабельников А.А. 2013. Особенности конвергентной журналистики. Вестник ун-та Российской Академии Образования, 3: 79-83.

8. Градюшко А.А. 2014. Сетевой текст как особый продукт творческой деятельности в веб-журналистике. Вестник Полоцкого гос. ун-та. Сер. А. Гуманитарные науки, 10: 144-148.

9. Градюшко А.А. 2018. Белорусские интернет-СМИ в контексте меняющегося медиапотребления. Журнал Белорусского гос. ун-та. Журналистика. Педагогика, 1: 4-11.

10. Ивченков В.И. 2018. Медиадискурс современности: стилистические приоритеты и экстралингвистические факторы. Актуальные проблемы стилистики, 4: 71-76.

11. Ивченков В.И. 2018. Мультимедийность. В кн.: Медиалингвистика в терминах и понятиях: словарь-справочник. Под ред. Л.Р. Дускаевой. М., ФЛИНТА: 399-402.

12. Ивченков В.И. 2019. Новые модели коммуникации и стилистические приоритеты современного медиадискурса. Медиалингвистика, 6 (1), 135-144. DOI: https://doi.org/10.21638/spbu22.2019.110 $348 \mathrm{c}$.

13. Интернет-СМИ: теория и практика. 2010. Под ред. М.М. Лукиной. М., Аспект Пресс,

14. Ким М.Н. 2013. Основы теории журналистики. СПб., Питер, 288 с.

15. Лущинская О.В. 2019. Дискурсный анализ как научный метод исследования конвергентных средств массовой коммуникации. Вестник Минск. гос. лингв. ун-та. Сер. 1, Филология, 6 (103): 28-35.

16. Олешко Е.В. 2018. Конвергентная журналистика: профессиональная культура как фактор оптимизации информационно-коммуникативных процессов. Автореф. дис... докт. филол. наук. Воронеж, $52 \mathrm{c.}$

17. Пак Е.М. 2012. Конвергенция жанров сетевой журналистики. Вестник СанктПетербургского ун-та. Сер. 9, Филология. Востоковедение. Журналистика, 2: 268-276.

18. Симкачева М.В. 2015. Процесс конвергенции СМИ и его влияние на формирование современного медиаполя. Ученые записки Казанского ун-та. Сер. Гуманитарные наки, 157 (4): $118-126$.

19. Хелемендик В.С. 2013. Конвергенция как современная форма взаимодействия СМИ. Проблемы современного образования, 3: 106-123. URL: http://pmedu.ru/index.php/ru/zhurnaly-2013g/vypusk-3 (дата обращения: 13.10.2020). 
20. Шестеркина Л.П. 2011. Формирование инновационной модели подготовки журналистов в контексте становления конвергентных СМИ: гуманитарный и технологический аспекты. Автореф. дис... докт. филол. наук. Москва, 52 с.

\section{References}

1. Baranova E.A. 2019. Mediakonvergentsiya kak sistemoobrazuyushchiy faktor transformatsii instituta SMI [Media convergence as a system-forming factor in the transformation of the media institution]. Abstract. dis... doct. philol. sciences. Moskva, $30 \mathrm{p}$.

2. Bastron A.A., Zheludeva E.V. 2016. Mediakonvergentsiya v zhurnalistike: ot klassiki k universal'nosti [Media Convergence in Journalism: From Classics to Universality]. RSUH / RGGU Bulletin. Ser. Records Management and Archival Studies. Computer Science. Data Protection and Information Security, 3(5): 33-45.

3. Biryukova T.A. 2017. Gipertekstovaya onlayn-zhurnalistika: istoriya vozniknoveniya (na primere elektronnogo zhurnala Feed) [Hypertext online journalism: history of origin (on the example of the electronic magazine Feed)]. Vestnik Moskovskogo universiteta. Seriya 10. Zhurnalistika, 3: 89-109.

4. Vartanova E. L. 2015. Novye media kak kul'turnoe prostranstvo sovremennogo obshchestva [New media as a cultural space of modern society]. MediaAlmanah, 4(69): 8-10.

5. Vorotnikova Yu.S. 2005. Realizatsiya novostnogo diskursa v elektronnykh angloyazychnykh SMI [Implementation of news discourse in electronic English-language media]. Abstract. dis... cand. philol. sciences. S.-Peterburg, $20 \mathrm{p}$.

6. Vyrkovskiy A.V. 2017. Upravlenie protsessami sozdaniya zhurnalistskogo teksta v pechatnykh i onlaynovykh SMI [Managing the Processes of Creation of Journalistic Text in Print and Online Media]. Abstract. dis... doct. philol. sciences. Moskva, 61 p.

7. Grabel'nikov A.A. 2013. Osobennosti konvergentnoy zhurnalistiki [Features of Convergent Journalism]. Herald of the University of the Russian Academy of Education, 3: 79-83.

8. Gradyushko A.A. 2014. Setevoy tekst kak osobyy produkt tvorcheskoy deyatel'nosti v vebzhurnalistike [Web text as a special product of creative activity in web journalism]. Vestnik of Polotsk State University. Part A. Humanities, 10: 144-148.

9. Gradyushko A.A. 2018. Belorusskie internet-SMI v kontekste menyayushchegosya mediapotrebleniya [Belarusian Internet Media in the Context of Changing Media Consumption]. Journal of the Belarusian State University. Journalism and Pedagogics, 1: 4-11.

10. Ivchenkov V. I. 2018. Mediadiskurs sovremennosti: stilisticheskie prioritety i ekstralingvisticheskie factory [Media discourse of our time: stylistic priorities and extralinguistic factors]. Aktual'nye problemy stilistiki, 4: 71-76.

11. Ivchenkov V.I. 2018. Mul'timediynost' [Mul'timediynost]. In Medialingvistika v terminakh i ponyatiyakh: slovar'-spravochnik [Medialingvistika v terminakh i ponyatiyakh: slovar'-spravochnik]. Ed. L.R. Duskaevoy. M., Publ. FLINTA: 399-402.

12. Ivchenkov V.I. 2019. Novye modeli kommunikatsii i stilisticheskie prioritety sovremennogo mediadiskursa [New models of communication and stylistic priorities of modern media discourse.]. Media Linguistics, 6 (1), 135-144. DOI: https://doi.org/10.21638/spbu22.2019.110

13. Internet-SMI: teoriya i praktika [Internet media: theory and practice]. 2010. Ed. M.M. Lukina. M., Publ. Aspekt Press, 348 p.

14. Kim M.N. 2013. Osnovy teorii zhurnalistiki [Foundations of the theory of journalism]. SPb., Publ. Piter, 288 p.

15. Lushchinskaya O.V. 2019. Diskursnyy analiz kak nauchnyy metod issledovaniya konvergentnykh sredstv massovoy kommunikatsii [Discourse analysis as a scientific method for the study of convergent mass communication]. Minsk State Linguistic Theoretical-scientific journal University Bulletin. Ser. 1 Philolougy, 6 (103): 28-35.

16. Oleshko E.V. 2018. Konvergentnaya zhurnalistika: professional'naya kul'tura kak faktor optimizatsii informatsionno-kommunikativnykh protsessov [Convergent Journalism: Professional Culture as a Factor for Optimizing Information and Communication Processes]. Abstract. dis... doct. philol. sciences. Voronezh, $52 \mathrm{p}$.

17. Pak E.M. 2012. Konvergentsiya zhanrov setevoy zhurnalistiki [The Convergence of Online Journalism Genre]. Vestnik Sankt-Peterburgskogo un-ta. Ser. 9, Filologiya. Vostokovedenie. Zhurnalistika, 2: 268-276. 
18. Simkacheva M.V. 2015. Protsess konvergentsii SMI i ego vliyanie na formirovanie sovremennogo mediapolya [The process of media convergence and its impact on the formation of the modern media field]. Uchenye Zapiski Kazanskogo Universiteta. Ser. Gumanitarnye Nauki, 157 (4): 118-126.

19. Khelemendik V.S. 2013. Konvergentsiya kak sovremennaya forma vzaimodeystviya SMI [Convergence as a modern form of media interaction]. Problems of modern education, 3: 106-123. URL: http://pmedu.ru/index.php/ru/zhurnaly-2013-g/vypusk-3 (accessed: 13.10.2020).

20. Shesterkina L.P. 2011. Formirovanie innovatsionnoy modeli podgotovki zhurnalistov v kontekste stanovleniya konvergentnykh SMI: gumanitarnyy i tekhnologicheskiy aspekty [Formation of an innovative model for training journalists in the context of the formation of convergent media: humanitarian and technological aspects]. Abstract. dis... doct. philol. sciences. Moskva, 52 p.

\section{ИНФОРМАЦИЯ ОБ АВТОРЕ}

Лущинская Ольга Владимировна, кандидат педагогических наук, доцент, заведующая кафедрой международной журналистики факультета журналистики, докторант кафедры медиалингвистики и редактирования факультета журналистики Белорусского государственного университета, г. Минск, Республика Беларусь

\section{INFORMATION ABOUT THE AUTHOR}

Olga V. Lushchinskaya state University, Minsk, Republic of Belaru, candidate of pedagogical Sciences, associate Professor, head of the Department of international journalism, faculty of journalism, doctoral student of the Department of media linguistics and editing, faculty of journalism, Belarusian 